http://dx.doi.org/10.23925/2176-2767.2018v61p416-433

Recebido em: 11/02/2018 Aprovado em: 26/02/2018

\title{
NOTÍCIA DE PESQUISA
}

\section{O LAZER NA CONTEMPORANEIDADE URBANA: INDUSTRIALIZAÇÃO, METRÓPOLE E A PRECONIZAÇÃO DO LAZER}

\author{
ALEXANDRE FRANCISCO SILVA TEIXEIRA*
}

\section{Introdução}

Esta pesquisa, em processo, orienta-se por fatos ocorridos sobre a institucionalização do lazer dos trabalhadores do comércio na cidade de São Paulo. Entre manifestações e estratégias relacionadas à categoria em questão encontra-se o Serviço Social do Comércio do Estado de São Paulo - SESC/SP instituição que realiza ações no campo do lazer há mais de 70 anos e compõe genericamente o sistema "S", que representa um conjunto de empresas patronais da indústria, do comércio, dos transportes e da agricultura. Tais instituições são classificadas como "Serviços Sociais Autônomos", ou seja, são administradas pelos poderes privados, possuem patrimônio próprio, direção particular, organizam seus serviços como uma empresa privada controlada pelo Tribunal de Contas da União.

Antes de 1969 os debates sobre o lazer das classes trabalhadoras já ocorriam no Brasil, principalmente na cidade de São Paulo e mesmo 
que de forma gradual e desigual, começam a ganhar expressão nos discursos políticos e econômicos (SANT' ANNA, 1994). Neste sentido o SESC, que até então, mantinha uma ação de cunho assistencialista, coloca em pauta na "IV Convenção Nacional de Técnicos" novos formatos para ação institucional embasado nas pesquisas acerca da sociologia do lazer, realizadas por Joffre Dumazedier - consultor da instituição para estudos no campo do lazer.

Na década de 1980 o cotidiano das grandes cidades no Brasil está ocupado preponderantemente por uma relação laboriosa na vida de seus habitantes. Nesta mesma década o SESC/SP aumenta o número de Centros Culturais na capital paulistana que vão do centro às periferias. Atualmente, na cidade de São Paulo, os equipamentos da instituição são encontrados em todas as zonas municipais como territórios para a fruição de um lazer cultural, diversificado e voltado às diferentes faixas etárias dos empregados do comércio, serviços e suas famílias.

A investigação pretende levantar transformações e permanências nas práticas do lazer institucional na cidade de São Paulo.

\section{O lazer como questão social}

Entre as transformações que ocorreram no século $\mathrm{XX}$, influenciadas pelo avanço do capitalismo, está a preconização do lazer nas cidades como uma questão social.

Mesmo com a justificativa de fortalecimento industrial, a difusão do lazer nas classes trabalhadoras impactou culturalmente as elites, que representadas pela polícia, pela justiça, pelo setor privado e pela Igreja 
tomam à frente da questão do lazer definindo conceitos, práticas e espaços.

A organização dos lazeres nega prontamente qualquer integração com o ócio, tal distinção tomou como base a ordem dos padrões de decência que instituíram o ócio como coisa imoral. Por exemplo, em 1825 a Intendência Geral da Polícia e seus comissários adotaram providências públicas de intolerância com relação a divertimentos relacionados a determinados jogos, a costumes escandalosos, a homens vadios, a desertores e a indivíduos sem ofício ou emprego. Salienta Sant'Anna (1994) “o ócio induzia à vagabundagem, à capoeiragem e aos vícios prejudiciais ao desenvolvimento físico e moral”.

A conduta nos usos dos corpos, como queriam as elites, para o tempo oposto ao trabalho da população urbana, intensificam-se quando o lazer gratuito surge como utilidade de consumo público. Para a população citadina, os novos códigos relativos ao tempo do não trabalho foram paulatinamente tomando o lugar das antigas formas que habitavam os momentos de descanso e ócio.

\begin{abstract}
"O cafuné, por exemplo, foi por muito tempo uma prática comum entre as brasileiras que entregavam suas cabeleiras às mãos hábeis e envolventes de suas mucamas prediletas, que mexiam para todos os lados a raiz dos cabelos de suas senhoras, estalando piolhos e provocando um prazer indescritível" (SANT'ANNA, 1994, p. 21).
\end{abstract}

Hábitos como o do "cafuné" foram deixando de ser públicos para tornarem-se reclusos ao mundo doméstico, sua redefinição foi 
influenciada pelas novas regras de beleza e higiene trazidas pelo crescimento das cidades.

Os espaços de lazer implantados na metrópole durante a primeira metade do século XX como os jardins, as praças, os Clubes Esportivos e os Centros Sociais compartilhavam das políticas que pretendiam inserir regras de higiene e conduta moral. A prática do lazer espalha-se pela sociedade conduzida pela questão social e pelo desejo de um corpo saudável, ágil e jovem. Estes estímulos traduziram, até certo ponto, a intenção das elites econômicas e intelectuais em "civilizar" as populações para a modernização do Estado.

A política dos serviços sociais promovidos pela Federação do Comércio do Estado de São Paulo, após 1946, é um exemplo dessas intervenções entre os comerciários. Seus Centros Sociais compartilharam a política nacional de modernização ao realizarem uma programação focada no avanço profissional e físico. Nesse momento a instituição estava conduzida por um forte conceito assistencialista em sua programação.

Com a legislação trabalhista de 1934 a questão social passou a ser vista como parte significativa para a nação, que estava tomada pelas ideias do Estado Novo. A chamada 'Questão Social' torna-se questão legal, sobretudo em virtude do aparecimento da CLT uma das principais preocupações de Getúlio em seu primeiro governo.

\footnotetext{
"O projeto político estadonovista distingui-se dos regimes anteriores por afastar-se das meras preocupações formais com procedimentos e modelos jurídicos para mergulhar nas profundezas
} 
de nossas questões econômicas e sociais" (FIGUEIREDO, 1991, p. 21).

Coligados a conjuntura política daquele momento onde a Questão Social e o Estado Nacional focavam as condições de vida do trabalhador, surgiram os sindicatos patronais organizados em federações e confederações por área de produção. Tais instituições pretendiam consensualizar interesses de classe e produtividade. Assim, a política assistencialista, que foi um forte braço do nacionalismo em ascensão do governo federal de 1930 no Brasil, orientou-se pela educação e pela cultura.

A partir de 1937, com a implantação efetiva do Estado Novo, essas propostas se intensificaram no discurso do governo Vargas, visando à formação do futuro do trabalhador brasileiro. Três anos mais tarde foi criado o Departamento Nacional da Criança subordinado ao Ministério da Educação e Saúde. Durante a organização deste departamento, surgiram também outros organismos sociais locais, criados pelo governo, como: a Legião Brasileira de Assistência, a Campanha Nacional dos Educandários Gratuitos, a Instituição de Puericultura e o Clube dos Menores Operários nos Parques Infantis.

É importante salientar que a modernização autoritária, presente nas primeiras décadas do século XX no Brasil, apoiaram-se a um forte pensamento racionalista de gestão científica do Estado. Assim, por meio de instituições culturais aplicavam-se métodos com perspectivas para integração da vida social. Este formato é reconhecido também por industriais, comerciantes, engenheiros, sanitaristas e educadores que se mobilizavam no Estado Novo de forma autônoma. 
"Serão eles que, organizando-se após a fim do Estado Novo, conduzirão em meados dos anos 1940 uma atuação mais intensa na sociedade que resultará na criação de instituições como o SESI, o SESC e o SENAC, buscando atender à área de serviço social da indústria e do comércio sem a intervenção direta do Estado" (DINES, 2012, p. 57).

Por esses fatos, o lazer e as questões sociais no Brasil foram discutidas em âmbitos práticos legais no Ministério do Trabalho e da Justiça, encabeçadas pelo ministro Alexandre Marcondes Filho, advogado paulista especializado em direto comercial, que já havia sinalizado em seu discurso de posse para a questão da sindicalização corporativa. Nota-se em seu discurso de posse em dezembro de 1941, um conjunto de medidas dirigida especificamente à questão da sindicalização corporativista aliadas a ideologia ministerial por ele delineada em sua administração. Esta política ministerial transitou muito bem entre os representantes das classes produtoras e pretendia desenvolver ações que englobassem a vida social dos trabalhadores nas seguintes questões: higiene, saúde, estrutura familiar, habitação e lazer (FIGUEIREDO, 1991).

Ao fim do período estadonovista outras questões econômicas, sociais e políticas apontavam no horizonte das grandes cidades brasileiras, entre elas, as mais relevantes foram as reduções das importações, a desaceleração industrial e os processos de redemocratização da nação. As populações citadinas estavam abaladas por estas novas condições, as estruturas sociais das cidades de maior porte passaram a sofrer com a insatisfação dos operários que em regime 
de greve de trabalho interferiram principalmente na produção industrial (GOMES, 2005).

Entre os anos de 1946 a 1956, a organização dos lazeres torna-se um forte recurso nas mãos das elites econômicas na orientação massiva dos comportamentos da população, visando avanço de seu desempenho produtivo. Para atender as necessidades deste contexto entram em cena a família, os cuidados higiênicos com o corpo e com a casa, a segurança doméstica, o concurso de robustez infantil, os cursos de aprendizagem comercial e os esportes (GOMES, 2005).

As imagens a seguir foram utilizadas para divulgação das programações do SESC em seus Centros Sociais na capital paulista em 1956 e exemplificam alguns formatos de ações da instituição no cotidiano dos comerciários paulistanos. Respectivamente, na imagem 1 notam-se orientações práticas da assistência à saúde e ao desenvolvimento físico e intelectual na primeira infância balizados principalmente pelas normas médicas. Essas práticas eram realizadas no Centros Sociais da Instituição e dirigidas principalmente as famílias de comerciários. Na imagem 2, a participação do SESC em eventos cívicos demonstra sua preocupação em mostrar-se publicamente em tais datas como registrado no desfile de 7 de setembro de 1956 na Avenida Anhangabaú na cidade de São Paulo, onde comerciárias carregaram estandartes exibindo escudos da instituição.

\section{As forças produtivas do lazer}


Estudiosos da área afirmam que o lazer surge na Europa no século XIX como um reflexo da revolução industrial nos centros urbanos significativos e principalmente na Inglaterra.

"Para muitos estudiosos, entre os quais se destaca Dumazedier, o lazer surgiu na modernidade europeia do XIX como fruto da revolução industrial ocorrida, naquele tempo, nos principais centros urbanos da Europa e principalmente na Inglaterra" (GOMES E ELIZALDE, 2012, p. 73).

Um marco para o lazer na modernidade é a militância socialista realizada por Paul Lafargue 1883, genro de Karl Marx, que cria panfletos que apoiavam o lazer operário abrindo uma brecha crítica sobre as questões do trabalho. Em sua obra "O direito a preguiça", há um lamento pelas perdas dos momentos de repouso e descanso do trabalhador que foram massacrados pela modernidade industrial. Lafargue faz referência aos capitalistas ingleses e menciona a forma inteligente como conduzem o trabalho. A medida tomada pelos ingleses em diminuir as horas de trabalho e adicionar mais dias de pagamento e feriados reforçou a produtividade.

"Eis a grande experiência inglesa, eis a experiência de alguns capitalistas inteligentes, ela demonstra irrefutavelmente que, para reforçar a produtividade humana, tem de se reduzir as horas de trabalho e multiplicar os dias de pagamento e os feriados, e o povo francês não está convencido" (LAFARGUE, 1883, p. 131).

Contrária à óptica da economia francesa da época e contrapondo a ordem social capitalista o manifesto de Lafargue esclarece que menos horas de trabalho gerariam maior produtividade e 
enriquecimento para a nação. "Ah! Como papagaios da Arcádia repetem a lição dos economistas: Trabalhemos, trabalhemos para aumentar a riqueza nacional. Ó idiotas! É por que trabalhais demais que a ferramenta industrial se desenvolve lentamente" (LAFARGUE, 1883, p. 132).

$\mathrm{O}$ vínculo entre lazer e trabalho consolida-se no século XX a partir da sociologia. Isto sugere uma direção, muitas vezes, contrária ao conceito de tempo livre (ADORNO, 1995).

O sociólogo Domenico de Mais em sua obra "O ócio Criativo" destaca que o trabalho ocupa o maior tempo de vida das pessoas e que pode ser executado também em ambientes lúdicos e descontraídos.

"O publicitário que deve criar um slogan, o jornalista em busca de uma 'dica' para um artigo, o juiz às voltas com a pista de um crime têm todos maior chance de encontrar a solução justa, passeando ou nadando, ou indo ao cinema, do que se ficarem trancafiados nas corriqueiras, tediosas e cinzentas paredes dos seus respectivos escritórios" (DE MAIS, 2000, p. 314).

A perspectiva existencial das populações citadinas passa pelo uso do tempo oposto ao trabalho como um tempo sem limites para a realização de seus desejos. Este comportamento abre um grande filão para a indústria do entretenimento. Assim, a distração, o regozijo, o jogo, o deleite, a festa e o passeio encontram lugar produtivo e lucrativo. O consumo de brinquedos, equipamentos esportivos, eventos culturais e atividades físicas instalam-se efetivamente no cotidiano das populações citadinas.

As formas de ocupar o tempo livre de obrigações do trabalho tornam-se cada vez mais importantes, tanto quanto, o tempo que se 
destina ao trabalho. Salienta DE MASI (2000, p. 314) "Em outras palavras, nos anos passados foi o trabalho que colonizou o tempo livre, nos anos futuros será o tempo livre a colonizar o trabalho".

Uma das iniciativas entre o empresariado que aproximou lazer e trabalho ocorreu na primeira metade do século XX. A "Conferência Nacional das Classes Produtoras" foi realizada em Teresópolis no Estado do Rio de Janeiro de 01 a 06 de maio de 1945 e reuniu mais de 800 associações de todo país. Seu resultado final gerou um documento chamado "Carta da Paz Social". Esta carta surge a partir dos debates realizados para orientar os caminhos a serem seguidos pelos grupos empresariais para uma melhor convivência entre patrões e empregado.

Em um de seus itens sugere a criação de um fundo social destinado às obras e ações que melhorassem a vida do trabalhador no âmbito de seu bem-estar social, por meio de uma obra educativa que fortalecesse a solidariedade, a confiança, a cultura e o aperfeiçoamento técnico. Por bem-estar dos trabalhadores entendia-se não só melhoria dos níveis de vida, como também aperfeiçoamento cultural e profissional.

\begin{abstract}
A "Carta de Teresópolis", como também foi denominada, ao se referir à criação de um fundo social objetivava uma proposta de conciliação de interesses entre empregadores e empregados. As relações entre estes grupos naquele momento mantinham um tom hostil, o que atrapalhava muito o avanço da produtividade pretendida (TEIXEIRA, 2015, p. 24).
\end{abstract}

Tal mobilização política realizada pelos empresários, rumo ao "bem-estar" da maioria, alcançou visibilidade junto ao poder executivo 
com sucesso. Assim, foi ratificado pela presidência da república em 13 de setembro de 1946, o Decreto-Lei 9.853 que autorizava realização de serviços sociais com administração descentralizada e presidida por representantes sindicais do comércio e de serviços nas esferas nacionais e regionais.

Além disso, o Decreto-Lei em questão permitia que os recursos de capital para tais ações fossem calculados a partir de um percentual da folha de pagamento e recolhidos compulsoriamente dos empregadores de estabelecimentos representados por sindicatos subordinados ao Conselho Nacional do Comércio de Bens - CNC em concordância com a Conciliação das Leis de Trabalho - CLT.

Como consequências destas jurisdições, os "Serviços Sociais" mantidos por setores de produção privados representaram um singular espaço nas estruturas legais do Brasil. Essas entidades foram definidas como paraestatais com autonomia jurídica e administrativa e elegem seus diretores sem ingerência estatal por meio de acordos sindicais, tem liberdade na gestão de seu patrimônio e prestam conta a posteriori ao Tribunal de Contas da União.

No caso do Serviço Social do Comércio em suas primeiras décadas, o lazer foi implantando como uma estratégia destinada a melhorar a qualidade de vida dos comerciários e assim diminuir resistências e tensões entre trabalhadores e empregadores. Estas ações contemplavam o plano de interesses expansionistas da política econômica do Estado Novo e que se mantiveram durante o regime militar. 
A arriscada tentativa de compreensão histórica das práticas do lazer na contemporaneidade urbana da cidade de São Paulo sugere que os representantes dos setores comerciais e industriais estão fortemente ligados à sua preconização popular na metrópole paulistana. O SESC é um fenômeno confirmatório para tal compreensão, seus Centros Culturais e suas programações são a prova cabal da produção cultural, esportiva e artística fortemente marcante no lazer dos paulistanos há décadas.

\section{A sonhada civilização do lazer}

Constatou-se que o tempo livre dos trabalhadores, especialmente na cidade de São Paulo, em torno do lazer foi assunto para jornais, revistas e encontros de variadas vertentes da sociedade, porém o tempo livre foi reduzido intensamente Tal contraditoriedade para "A civilizạ̧ão do lazer" profetizada entre sindicatos e trabalhadores tornou-se um contrassenso em face da impossibilidade da redução do tempo de trabalho que aumentava descaradamente diante das leis trabalhista. (SANT'ANNA, 1994)

$\mathrm{O}$ que ocorreu naqueles anos foi um arrocho salarial dos setores bancários e comerciais que colocou o lazer em patamares de luxo. As ocorrências entre trabalho e lazer se justificam na vida dos trabalhadores remunerados, contribuindo para o sentido do lazer como um privilégio após o dever do trabalho cumprido. Assim, o desejo pelo tempo livre aumenta durante o tempo de trabalho, nele residem o sonho, a utopia e a redenção daquilo que é penoso e obrigatório. O prazer em gozar o tempo livre é semelhante à ideia de liberdade como uma recompensa do 
trabalho que se tornou o lugar do rotineiro, do árduo e do irrisório, como um castigo.

O sociólogo Joffre Dumazedier em meados de 1960 pontuou que os lazeres são práticas que estão relacionadas às classes sociais do trabalho e correspondem de certa forma, a um referencial cultural, econômico, educacional e social ao qual pertence um grupo ou indivíduo. Estas constatações sobre as formas do lazer são resultados de uma análise multivariada com respostas variadas. "Decompusemos o lazer e o trabalho em dimensões variadas, introduzimos as diferenças de idades e as diferentes condições sócio profissionais. Qual a resposta dada por nossa análise multivariada? Uma resposta variada" (DUMAZEDIER, 2008, p. 145).

A realidade das cidades no século XX esteve dominada pelo trabalho e pela produtividade e assim, revela-se complexa e ambígua. Da mesma forma o lazer divide opiniões que transitam entre considerá-lo um tempo para recuperação das forças do trabalho ou de realização pessoal.

Já na sociedade industrial nascente, os teóricos das soluções socialistas se dividem. Uns dão ênfase ao trabalho como fim das atividades humanas, enquanto para outros o trabalho é um 'dogma desastroso' se não for reduzido ao papel de um simples instrumento. Aos olhos de uns, o tempo livre é um meio de recuperação da força de trabalho para outros, é um quadro de realização do homem. (DUMAZEDIER, 2008, p. 131)

O lazer nos Estados Unidos surge com a obra de T. Veblen "The theory of the leisure class" (1889), obra que passa por estudos 
sobre as formas de ociosidade da burguesia e sobre o lazer dos trabalhadores e parte de pressupostos que indicam que o lazer é uma reafirmação do tempo de trabalho como se fosse o reverso de uma mesma moeda e muito distante dos momentos de ócio. "A ociosidade nega o trabalho, os lazeres o supõem” (DUMAZEDIER, 2008, p. 20).

Nos anos de 1920 -1930 na Europa e nos USA ocorrem um aprofundamento dos estudos sobre a sociologia do lazer pontuados sob o efeito do surgimento da jornada de 8 horas de trabalho como uma importante conquista para a classe trabalhadora. No mesmo período ocorre em Genebra, organizado pelo "Bureau Internacional do Trabalho", o $1^{\circ}$ Congresso Internacional acerca do Tempo Livre dos Trabalhadores. Entre os trezentos membros de dezoito nações, as discussões foram acerca da organização dos lazeres no tempo liberado do trabalho, que neste momento se expandem com a conquista da "semana inglesa" com 8 horas de trabalho diário. A partir deste formato implantado na Inglaterra o trabalho passa a ter uma organização específica orientada por rotinas alternadas em momentos de trabalho e não trabalho.

O tempo nitidamente separado do trabalho e destaca-se no cotidiano urbano das populações com periodicidade semanal, mensal ou anual. "Com a intensificação da industrialização as relações de trabalho sofrem mudanças: o tempo de trabalho passa a ser mais delimitado e consequentemente o tempo fora do trabalho também merece atenção" (FIGUEIREDO, 1991, p. 64). 
Isto não significa que o lazer esteja garantido no tempo livre dos trabalhadores, o lazer é uma atitude organizada que pode visar o desenvolvimento integral de um sujeito que se disponibiliza a realizá-lo.

\begin{abstract}
"Costuma-se pensar que tempo livre e lazer são a mesma coisa, mas todo mundo pode ter tempo livre, mas todos podem ter lazer? O tempo livre é uma ideia de uma democracia realizável. O lazer não é por todos realizável, por tratar-se de uma atitude e não de uma ideia. Lazer é a harmonia individual entre a atitude, disponibilidade de si mesmo e o desenvolvimento integral" (GAELSER, 1986, p. 42).
\end{abstract}

Muitos fatores culturais provenientes das classes empregadoras exerceram influência sobre o modo de organizar o lazer no tempo livre. Para aqueles que entendiam o tempo após do trabalho, como um momento propício a articulação de ideias contrárias à expansão econômica, um momento de reuniões, de lamentar o cansaço do dia a dia, dos sonhos não alcançados, dos botequins e do não fazer nada. O lazer sugeria uma ameaça ao controle da produtividade comercial e industrial.

Surgiu assim, a racionalização do trabalho, que articulou ideias para que o tempo livre fosse ocupado por uma regulamentação que penetrasse os ambientes domésticos dos operários com conselhos para educação familiar, e assim, sugerindo princípios de ordem e economia. Formatos que não consideravam parte do lazer divertimentos que ocorressem espontâneos ou relacionados à manifestação livre das classes trabalhadoras por serem classificados como ociosidade ou barbárie (LEMOS, 2005). 
A criação de certos programas que conferem diversão e ludicidade tem o objetivo estratégico de normalização de um trabalhador disciplinado. A exemplo deste formato no Brasil, o SESC promovia e suas primeiras décadas um lazer sob uma política e concepção produtiva e não muito distante do trabalho. Formas de promoção do lazer que ainda estavam vinculadas às políticas governamentais que objetivaram apaziguar as relações entre patrão e empregado.

Mas nem tudo que se refere ao lazer é vinculado à produtividade ou a indústria cultural, a valorização da ludicidade no tempo do não trabalho é reconhecida como saudável na vida de todos.

\section{Conclusão}

Não uma tarefa fácil avaliar cronologicamente as práticas do lazer institucional, entretanto esta pesquisa tratou de fazê-lo sob o prisma da formação metropolitana na cidade de São Paulo. Assim, estabeleceu como marco cronológico 1940, quando as forças do trabalho urbano juntamente com o processo de industrialização passam a organizar o lazer como questão social.

Quando os setores de produção industrial e comercial do Estado de São Paulo e do Rio de Janeiro, representados pelos empresários da indústria e do comércio, estabeleceram acordos patronais junto as representações sindicais e governamentais. Supunham implantar equipamentos de lazer integrados a cidade, com vistas para o aumento da produtividade, organização e controle social. Estes grupos da elite 
econômica brasileira estavam respaldados pela questão social que foi uma forte política governamental na década de 1940.

O Serviço Social do Comércio - SESC torna-se realidade no Estado de São Paulo em 1946, ambientado pelo assistencialismo e orientado pela "Carta da Paz Social" que foi o resultado documental do encontro dos empresários dos setores de produção industrial e comercial em Teresópolis-RJ em 1945. O SESC, atravessou várias décadas consolidando-se na cidade como um território diversificado e destinado prioritariamente aos trabalhadores do comércio, porém com certa abertura para o público em geral. Sua programação orienta-se por conceitos carregados de representações culturais e educativas.

Assim, o cotidiano das cidades, principalmente a partir de meados do século XX, foi atravessado pela institucionalização do lazer como um tempo produtivo que penetrou nos hábitos privados, fortaleceu os gostos e modos segundo a norma culta, orientou a atividade física e conduziu um modo estético no viver citadino colonizado pela modernidade desenvolvimentista. Logo, o tempo do lazer superou o sentido restrito de descanso reparador de energias e passou a ser representado por um conjunto de possibilidades lúdicas, intelectuais, espirituais, corporais, comerciais e, sobretudo, culturais.

Desta forma, o lazer passou a ter lugar na cidade distintamente separado das obrigações do trabalho, porém proposto pelo próprio patronato. O que caracteriza um espaço/tempo para o lazer na cidade organizado por corporações privadas e detentoras do poder econômico.

Os fatos historiográficos apontados sugerem o lazer institucionalizado na contemporaneidade urbana adicionado de um 
grande objetivo genérico por meio da ordem do abstrato e do invisível. Por isso, suas imbricações tradicionais com o tempo livre foram ocupadas pelos esportes, pelas artes e pela educação sem mudar o fator que sustenta sua ideia principal, a fruição pela livre escolha na ocupação de seu tempo /espaço previamente organizados e programados.

\section{Notas}

* Doutorando de História Social na Pontifícia Universidade Católica de São Paulo - PUC-SP. Área de concentração: História, Cultura e Cidade; Linha de pesquisa: Lazer, Contemporaneidade Urbana e Centros Culturais. É integrante no Núcleo de Estudos de História Social da Cidade - NEHSC PUC/SP, onde realiza estudos e debates acerca da História do Lazer. 